\title{
Evaluation of the Effectiveness of Silica Gel Desiccant in Improving the Keeping Quality of Rice Crackers
}

\author{
A. M. Suweesha H. Amarakoon ${ }^{1}$, Senevirathne Navaratne ${ }^{2}$ \\ ${ }^{1,2}$ Department of Food Science and Technology, University of Sri Jayewardenepura, Sri Lanka
}

\begin{abstract}
Rice cracker is a hygroscopic product, produced from rice flour. Therefore, desiccants are used in the product to provide a moisture barrier property. The effectiveness of silica gel desiccant in improving the keeping quality of rice crackers is characterized in the present study based on the evaluation of physiochemical and microbiological quality of the rice crackers throughout its 6 months' shelf life. Four types of rice cracker samples were prepared by inserting $5 \mathrm{~g}, 2.5 \mathrm{~g}$, $1 \mathrm{~g}$ and no silica gel in sachets to each $100 \mathrm{~g}$ rice cracker packet. The samples were packed in double laminated wrapper and stored under ambient conditions. The samples were subjected to determine the changes occur in physical, chemical and microbiological properties throughout 6 months of shelf life. Water vapor transmission ratio (WVTR) of the packing material and time taken by silica gel to become saturated state were measured. Variation of hardness, moisture content, $\mathrm{pH}$, free fatty acid content (FFA), total plate count (TPC) of rice crackers were tested against period of storage. Results were analyzed using Minitab 17 statistical software. Results revealed that rice crackers packed with $5 g$ silica gel in sachet was able to maintain a lower moisture content, FFA value and hardness with the time than the other three samples. Thus, it was concluded that $5 \mathrm{~g}$ silica gel was the best amount of desiccant to protect the quality of $100 \mathrm{~g}$ rice crackers for a period of 6 months' shelf life.
\end{abstract}

Keywords: Rice crackers, Silica gel desiccant, Free fatty acid, Moisture content, Hardness

\section{Introduction}

Rice is the staple food for nearly half of the population in the world. Rice (Oryza sativa) is a dietary staple foods and one of the most important cereal crops, especially for people in Asia, but the consumption outside Asia has increased, recently (Orthoefer, 2005).

Sri Lanka used to consume rice mainly in boiled form and rice is not much used to process into other food types. In many instances wheat flour is the major ingredient in snacks. But due to the greater awareness about the celiac disease (gluten intolerance conditions), high nutrient content in rice including vitamins, innovative ideas of rice processing and being staple food of many Asian countries, instead of wheat flour, rice flour has been used in many food applications recently.

Rice is consumed mostly as cooked grains, and it is also processed to puffed rice (Joshi et al., 2014) \& rice flour \& starch which can then be converted to different products such as noodles, rice crackers etc. Sri Lanka recently introduced Rice Crackers which uses the rice flour as main ingredient. Initially a common base cracker is produced and it is flavored using several varieties of flavors to produce different types of rice crackers. After drying and baking of the crackers, oil is prayed to them for flavor adherence (Rajkumar et al., 2003).

Rice based cracker is a hygroscopic food product which easily absorbs water vapor. Therefore, the shelf life of the product can be shortened due to the loss of crispiness and flavor as well as the hydrolytic rancidity which can lead the product to produce off flavors and off odors. Thus, the moisture absorption by rice crackers leads to its quality deterioration and the palatability of the product can have a negative effect. The primary consideration for selecting and eating a food commodity is the product's palatability or eating quality. Other quality parameters such as nutrition and wholesomeness are secondary (Meiselman, 1996; Lawless and Heymann, 2010).

Loss of crispness due to moisture uptake is a major cause of snack food rejection by consumers (Robertson, 2006). There are several methods to retard the action of moisture absorption by the hygroscopic products. Using a packaging combination with good barrier properties for moisture, storing in a low relative humidity, using a desiccant inside the product are few of those mechanisms to reduce the rate of moisture absorption by the product. From these methods, using a desiccant is the most common.

Desiccant is considered as the active component. The active component may be a part of the packaging material or an insert into the package, such as a desiccant sachet (Marsh, 1997). Thus, as a remedy for the moisture absorption from rice crackers, silica gel desiccant in sachets were used in each rice cracker packet which is considered to have a scavenger property for water. Therefore, the main purpose of this study was to investigate the effect of silica gel desiccant on the physiochemical and microbiological quality of the product throughout its shelf life.

\section{Literature Review}

\subsection{Rice crackers}

In general, there is an increase in demand for ready to eat processed foods with better, shelf life, satisfying taste, easy of portability and with high nutritional quality. And that's because of the urbanization growth as well as the increase in 


\section{International Journal of Science and Research (IJSR) \\ ISSN (Online): 2319-7064}

Index Copernicus Value (2015): 78.96 | Impact Factor (2015): 6.391

the employment of women (Al-Shawabkeh and Mazahreh, 2009).

Rice cracker is one of the popular ready to eat food in the snack food market. Snack foods are an integral part of the diet and have been over a period of time commercially exploited on large scale. Crackers are the popular snack products which have appreciable demand amongst the consumers (Maneerote et al., 2009; Sedej et al., 2011). From these products, the cracker is the most important that can satisfy these requirements. Because these products do not need cold temperatures for preservation, they are popular for camping trips, hunting and fishing expeditions and other activities where refrigeration may not be available. In addition, they are convenient products to have on hand in your cupboard (Singh et al., 2000).

\subsection{Palm oil}

Palm oil is the major oil source used in rice cracker production. It is sprayed on to the baked rice crackers before flavoring for better adherence of flavor powder and to give a glossy appearance.

Palm oil is produced from the fruit of the oil palm tree Elaeis guineensis. Oil palm is the only fruit that can give two types of oil. Since it is not an animal source, it does not contain cholesterol. Virgin palm oil is rich in carotenoids (pro Vitamin A), tocotrienols and tocopherols (Vitamin E).

Palm fruit gives two type of oils; palm oil and palm kernel oil. Palm oil is extracted using the mesocarp or the flesh of the palm fruit while palm kernel oil is extracted from the endosperm of the fruit. Crude palm oil is refined to remove impurities. Refined oil is then separated into solid and liquid fractions - it is the liquid that is commonly used for cooking oil. Palm-kernel oil is extracted as a separate process, involving grinding, heating and the use of an soilseed expeller' or solvent (Poku, 2002).

Palm oil has a balanced ratio of saturated and unsaturated fatty acids. It has $40 \%$ oleic acid (monounsaturated fatty acid), $10 \%$ linoleic acid (polyunsaturated fatty acid), $45 \%$ of saturated palmitic acid and $5 \%$ of saturated stearic acid.

\subsection{Active packaging}

Active packaging materials are intended to sense internal or external environmental changes and to respond by offsetting the change in an otherwise suitable package (Marsh, 1997; Brody et al., 2001). Active package materials have also been referred to as -smart" and -fnctional" packaging. Active packaging, in conjunction with other food processing and packaging technologies, is able to enhance the quality and safety of the food and beverage products (Marsh, 1997).

Desiccants started the active packaging era with their addition into dry product packages to adsorb moisture. Desiccants can be contained in a moisture permeable sachet, pouch, patch, coupon, label, etc. The desiccant sachet is incorporated into the package to absorb water vapor from the contained product and from the package headspace, as well as any water vapor that enters by permeation or transmission through the package structure (Brody et al., 2001).

\subsection{Silica gel}

Silica gel is used as a desiccant in food and nonfood products. There are two types of silica gel such as indicating silica gel and non-indicating silica gel. Basically indicating silica gel has the Cobalt Chloride as the color indicator which is a salt of the heavy metal Cobalt. Therefore, indicating type silica gel is not used in contact with food products as it includes heavy metal cobalt. Non indicating type silica gel is widely used in food industry as a desiccant. Non indicating silica gel is cheap but effective. And it is available in bulk form and sachets. Silica gel is an inert material. It is nontoxic and nonflammable. Can be easily packed into breathable sachets or bags. Non indicating silica gel is one of the common desiccant used in contact with food and is approved safe by FDA. Silica gel is produced in hard forms such as granules which has the specific round shape, transparent and dry structure. The microporous structure in silica gel has the capacity to adsorb the water vapor into those cavities. The number of micro cavities on the surface of the silica gel granules can increase the efficiency of adsorption of water vapor. It can be reused if the adsorbed moisture is removed with gentle heating.

Basically there is no chemical reaction taken place in silica gel in adsorbing moisture. It is only the adherence of water vapor into the micro cavities of silica gel which happens due to the difference of water vapor gradient between the surrounding environment and the micro cavities in silica gel. Normally the water vapor pressure inside the cavities in silica gel is lower than the surrounding environment. Therefore, the moisture adsorption is taken place till the cavities are saturated or till the water vapor pressure of the surrounding environment and micro cavities have gained an equilibrium. Even after reaching its maximum adsorption, silica gel remains unchanged in shape and still appears as a dry product.

\section{Materials and Methods}

\subsection{Determination of WVTR of the packing material}

WVTR of the double laminated packing material which was used to pack the rice crackers was measured. Initially three pouches with same dimensions were made from the double lamination wrapper $(20 \mu \mathrm{BOPP}+12 \mu \mathrm{MET}$ PET $+25 \mu \mathrm{CO}$ EXCPP) with $60 \mu$ thickness and $66 \mathrm{gsm}$. Then $5 \mathrm{~g}$ of dehydrated silica gel was inserted into each pouch and the pouches were properly sealed and stored under ambient environmental conditions. The initial weight of the pouches and their weight gain in each week was recorded until a constant weight was observed.

\subsection{Determination of hardness of rice crackers}

TA1- Texture Analyzer (AMETEK group, USA) with the use of NEXYGEN Plus data analysis software was used to analyze the texture profile of crackers. Three-point bend rig was used to stress, deflect and break the cracker. The trigger 


\section{International Journal of Science and Research (IJSR) \\ ISSN (Online): 2319-7064}

Index Copernicus Value (2015): 78.96 | Impact Factor (2015): 6.391

force was set to 10.000 grams force and trigger speed was set to $100.00 \mathrm{~mm} / \mathrm{min}$. The span between the supports was $40 \mathrm{~mm}$. From each sample, 50 replicates were used. The hardness was determined by the maximum force in Newton force. The hardness value is considered as the maximum positive peak force on the graph. Significant difference in hardness values between the rice cracker samples were evaluated using one-way ANOVA. The hypothesis is written as follows;

$\mathrm{H}_{0} /$ null hypothesis $=$ All samples have the same mean.

$\mathrm{H}_{1}$ /alternative hypothesis = At least one mean is different from the others.

Significant difference was defined as $\mathrm{p} \leq 0.05$.

\subsection{Determination of moisture contents of rice crackers}

Rice crackers were grounded using the mortar and pestle and $5 \mathrm{~g}$ of the sample was put into the moisture analyzer. At, $108^{\circ} \mathrm{C}$ within 6 minutes the moisture content (\%) was recorded in the moisture analyzer.

\subsection{Determination of $\mathrm{pH}$ value of rice crackers}

Rice crackers were grounded using the mortar and pestle. Then, $5 \mathrm{~g}$ of the sample was put into the beaker and distilled water was poured into it up to $50 \mathrm{~g}$. After proper dissolution of the rice cracker powder in the distilled water, $\mathrm{pH}$ probe was dipped in it and $\mathrm{pH}$ value was recorded.

\subsection{Determination of FFA content}

Initially fat was extracted from the rice crackers using the soxhlet extraction method. For that, $15 \mathrm{~g}$ of rice crackers was grounded with the mortar and pestle. Then twice the weight of anhydrous sodium sulphate was added to it and grounded until a free flowing powder was obtained. Then the powdered material was transferred into the extraction thimble and the top open end was covered with cotton wool. Then the extraction thimble was placed in the soxhlet apparatus. A previously dried clean round bottom flask (250 $\mathrm{ml}$ ) was taken and $200 \mathrm{ml}$ of petroleum ether was added to it with few pumice chips. Then the flask was connected to the soxhlet extractor and the condenser was fitted. Then it was heated in a heating mantle and refluxed for nearly 4 hours. The heating rate was kept low enough to prevent the solvent escaping from the top of the condenser during refluxing. Once the refluxing was over, the solvent was distilled off by keeping the flask and its contents in a water bath at $60^{\circ} \mathrm{C}$. (Petroleum ether boiling point $40^{\circ} \mathrm{C}-60^{\circ} \mathrm{C}$ ). Then the flask was kept in an oven at $105^{\circ} \mathrm{C}$ for 2 hours. Then the flask and contents were cooled for 30 minutes in a desiccator and weighed. This procedure was repeated until a constant weight was obtained.

To determine the FFA value of the extracted fat, initially 25 $\mathrm{ml}$ of $95 \%$ ethyl alcohol and $25 \mathrm{ml}$ of di ethyl ether was mixed in a beaker with few drops of $1 \%$ phenolphthalein solution. The mixture was transferred to the conical flask and carefully neutralized with few drops of $0.1 \mathrm{M} \mathrm{NaOH}$ until a faint pink color persists. The extracted fat was dissolved in the neutral solvent and the mixture was titrated with $0.1 \mathrm{M} \mathrm{NaOH}$ until a pink color persists for at least 15 seconds.

\subsection{Determination of total plate count}

Initially $90 \mathrm{~g}$ of buffered peptone water was mixed in a polythene bag with $10 \mathrm{~g}$ of rice cracker under a laminar flow cabinet. Then the polythene bag was kept in the stomacher and the ingredients were mixed at 230rpm for 30 seconds. Then $1 \mathrm{ml}$ of the mixture inside the polythene bag was pipetted into a sterilized petri dish under a laminar flow cabinet. Then $15 \mathrm{ml}$ of plate count agar was poured into the petri dish and was rotated clockwise and anticlockwise for three times. Then it was kept without closing under the laminar flow cabinet for 2-3 minutes until the agar was solidified. Then the dishes were closed and kept in the incubator at $37^{\circ} \mathrm{C}$ for 48 hours. The number of colony forming units were counted (Colony forming units/g).

\section{Results and Discussion}

\subsection{Water vapor transmission ratio}

Water vapor transmission ratio of the double laminated wrapper $(20 \mu$ BOPP $+12 \mu$ MET PET $+25 \mu$ CO EXCPP $)$ with $60 \mu$ thickness and 66 gsm was calculated as $0.2786 \mathrm{~g}$ $\mathrm{m}^{-2}$ day $^{-1}$.

\subsection{Time for silica gel to become saturated with water vapor}

Mean weight gain in silica gel pouches against time for a period of 18 weeks is shown in figure 1 .

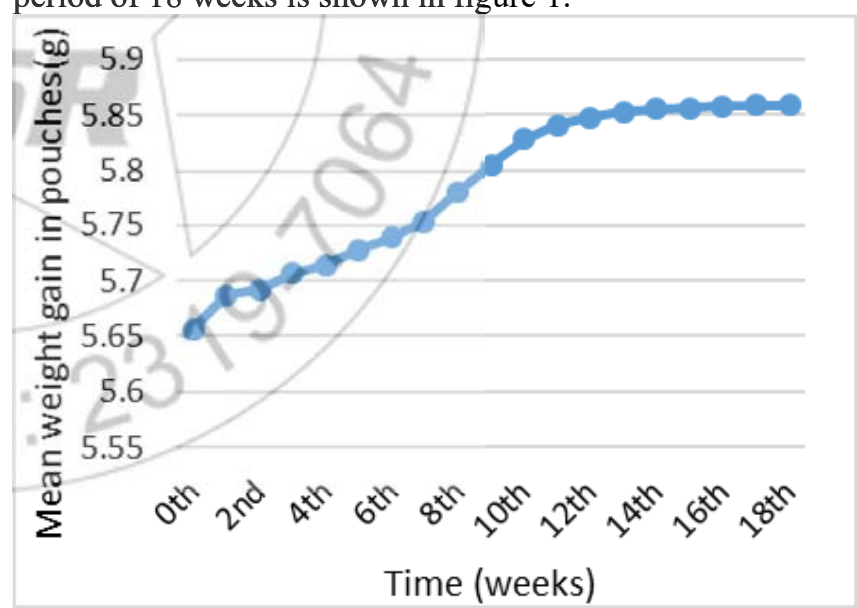

Figure 1: Mean weight gain in silica gel pouches with time

The graph given in figure 1 clearly indicates that silica gel takes around 12 weeks' time to become saturated state. Hence, effective period of silica gel as a desiccant is about 12 weeks under ambient environmental conditions.

\subsection{Hardness of rice crackers}

Hardness of rice crackers in mean force $(\mathrm{N})$ with standard deviation in each sample at one month intervals is shown in table 1 . 


\section{International Journal of Science and Research (IJSR) \\ ISSN (Online): 2319-7064}

Index Copernicus Value (2015): 78.96 | Impact Factor (2015): 6.391

Table 1: Hardness of rice crackers with time

\begin{tabular}{|c|c|c|c|c|}
\hline \multicolumn{5}{|c|}{ Hardness $(N)$} \\
\hline & \multicolumn{4}{|c|}{ Rice crackers $100 \mathrm{~g}$ packed with silica gel } \\
\hline Time (Months) & $0 g$ & $\lg$ & $2.5 g$ & $5 g$ \\
\hline $1^{\text {st }}$ & $\begin{array}{c}5.766 \pm \\
0.996^{\mathrm{a}}\end{array}$ & $\begin{array}{l}5.719 \pm \\
1.183^{\mathrm{a}}\end{array}$ & $\begin{array}{c}5.503 \pm \\
1.015^{\mathrm{a}}\end{array}$ & $\begin{array}{c}5.279 \pm \\
1.475^{\mathrm{a}}\end{array}$ \\
\hline $2^{\text {nd }}$ & $\begin{array}{c}6.677 \pm \\
0.899^{\mathrm{a}} \\
\end{array}$ & $\begin{array}{c}6.571 \pm \\
1.409^{\mathrm{a}} \\
\end{array}$ & $\begin{array}{c}6.217 \pm \\
1.052^{\mathrm{a}} \\
\end{array}$ & $\begin{array}{c}6.097 \pm \\
1.161^{\mathrm{a}} \\
\end{array}$ \\
\hline $3^{\text {rd }}$ & $\begin{array}{c}6.882 \pm \\
0.983^{\mathrm{a}}\end{array}$ & $\begin{array}{c}6.752 \pm \\
1.186^{\mathrm{a}} \\
\end{array}$ & $\begin{array}{l}6.532 \pm \\
1.487^{\mathrm{a}, \mathrm{b}}\end{array}$ & $\begin{array}{c}6.073 \pm \\
0.929^{\mathrm{b}}\end{array}$ \\
\hline $4^{\text {th }}$ & $\begin{array}{l}7.334 \pm \\
1.384^{\mathrm{a}}\end{array}$ & $\begin{array}{l}7.267 \pm \\
1.122^{\mathrm{a}}\end{array}$ & $\begin{array}{l}7.155 \pm \\
1.505^{\mathrm{a}}\end{array}$ & $\begin{array}{c}6.673 \pm \\
1.057^{\mathrm{a}}\end{array}$ \\
\hline $5^{\text {th }}$ & $\begin{array}{l}9.679 \pm \\
1.649^{\mathrm{a}}\end{array}$ & $\begin{array}{l}9.522 \pm \\
1.661^{\mathrm{a}}\end{array}$ & $\begin{array}{l}9.303 \pm \\
1.660^{\mathrm{a}}\end{array}$ & $\begin{array}{c}8.935 \pm \\
1.742^{\mathrm{a}}\end{array}$ \\
\hline $6^{\text {th }}$ & $\begin{array}{l}9.842 \pm \\
1.515^{\mathrm{a}}\end{array}$ & $\begin{array}{c}9.799 \pm \\
2.054^{\mathrm{a}} \\
\end{array}$ & $\begin{array}{c}9.804 \pm \\
1.513^{\mathrm{a}}\end{array}$ & $\begin{array}{l}9.200 \pm \\
1.673^{\mathrm{a}}\end{array}$ \\
\hline
\end{tabular}

Table 1 shows an increase in hardness of rice crackers in all samples with the time.

Basically, puffed snack products like rice crackers are more palatable with moderate hardness and crispiness. Therefore, increment of hardness is a negative effect on its sensory appeal.

The control sample has recorded the highest hardness each month whilst the rice crackers packed with $5 \mathrm{~g}$ silica gel showed the lowest hardness. Reason for this consequence was due to the effect of silica gel. Rice crackers have shown an increase in hardness as a result of moisture absorption.

According to (Chui, 2002), when the cracker absorbs moisture, the plasticizing effect of water increases the flexible movement of other molecules in the solid matrix of rice crackers. So when the compression force is applied, the rice cracker tends to have deformation which include resistance for fracturing. Thus, it results in higher hardness values which also implies a lower crispiness and an absence of a brittle structure.

A significant difference of hardness between the samples was shown in the $3^{\text {rd }}$ month due to the saturation of silica gel during the $3^{\text {rd }}$ month. Because of the absence of effective desiccation property during this period, crackers tend to absorb moisture in an increased rate (table 2). During this period, the water plasticizing effect has created a significant higher hardness in the control sample and in the rice crackers packed with $1 \mathrm{~g}$ silica gel.

\subsection{Moisture content}

Moisture content of rice crackers packed with different amount of silica gel against time is shown in table 2 .

Table 2: Moisture content of rice cracker samples with time

\begin{tabular}{|c|c|c|c|c|}
\hline & \multicolumn{5}{|c|}{ Rice crackers $100 \mathrm{~g}$ packed with silica gel } \\
\hline Time (weeks) & $0 g$ & $1 g$ & $2.5 g$ & $5 \mathrm{~g}$ \\
\hline $\mathbf{0}^{\text {th }}$ & 2.51 & 2.47 & 2.48 & 2.43 \\
\hline $\mathbf{2}^{\text {nd }}$ & 2.65 & 2.61 & 2.60 & 2.47 \\
\hline $\mathbf{4}^{\text {th }}$ & 2.75 & 2.71 & 2.69 & 2.51 \\
\hline $\mathbf{6}^{\text {th }}$ & 2.88 & 2.89 & 2.85 & 2.58 \\
\hline $\mathbf{8}^{\text {th }}$ & 3.02 & 2.93 & 2.90 & 2.61 \\
\hline
\end{tabular}

\begin{tabular}{|l|l|l|l|l|}
\hline $\mathbf{1 0}^{\text {th }}$ & 3.20 & 2.98 & 2.96 & 2.74 \\
\hline $\mathbf{1 2}^{\text {th }}$ & 3.44 & 3.31 & 3.22 & 3.04 \\
\hline $\mathbf{1 4}^{\text {th }}$ & 3.83 & 3.73 & 3.69 & 3.55 \\
\hline $\mathbf{1 6}^{\text {th }}$ & 3.91 & 3.87 & 3.83 & 3.62 \\
\hline $\mathbf{1 8}^{\text {th }}$ & 3.94 & 3.89 & 3.85 & 3.69 \\
\hline $\mathbf{2 0}^{\text {th }}$ & 3.98 & 3.91 & 3.89 & 3.71 \\
\hline $\mathbf{2 2}^{\text {nd }}$ & 4.12 & 4.05 & 3.91 & 3.74 \\
\hline $\mathbf{2 4}^{\text {th }}$ & 4.17 & 4.08 & 3.96 & 3.94 \\
\hline
\end{tabular}

The data given in table 2 clearly indicates that moisture content in all the cracker samples has been increased against time. Although all crackers samples were subjected to the same storage condition, they did not tend to absorb same amount of moisture.

Reason for the different rate of moisture absorption is due to the effect of silica gel. Rice crackers packed with $5 \mathrm{~g}$ silica gel recorded lower rate of moisture absorption throughout 6 months of storage. The highest moisture content was recorded in the control sample. The effect of $1 \mathrm{~g}$ and $2.5 \mathrm{~g}$ silica gel also showed a lower desiccation effect throughout the storage period.

The moisture absorption rate has a sudden increase in between $10^{\text {th }}-14^{\text {th }}$ week in the rice crackers packed with silica gel. This can be correlated with the saturation of silica gel at the end of $12^{\text {th }}$ week (figure 1). Thus, due to the absence of effective desiccation property of silica gel, crackers tend to absorb moisture in an increased rate from $10^{\text {th }}-14^{\text {th }}$ week of storage. Since there was an effect of silica gel on the moisture content of rice crackers, a regression analysis was performed for the moisture content and time. Regression models for the four rice cracker samples are shown in figure 2,3,4 and 5 .

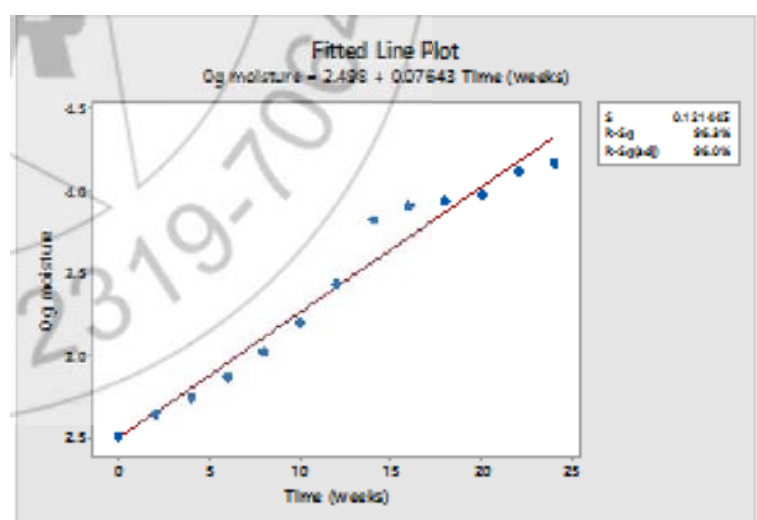

Figure 2: Fitted line plot for the control sample

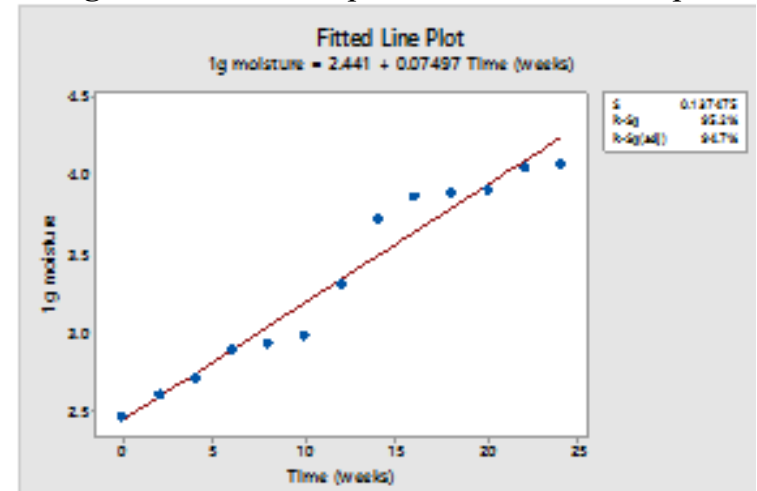

Figure 3: Fitted line plot for the rice crackers packed with $1 \mathrm{~g}$ silica gel 


\section{International Journal of Science and Research (IJSR) ISSN (Online): 2319-7064}

Index Copernicus Value (2015): 78.96 | Impact Factor (2015): 6.391

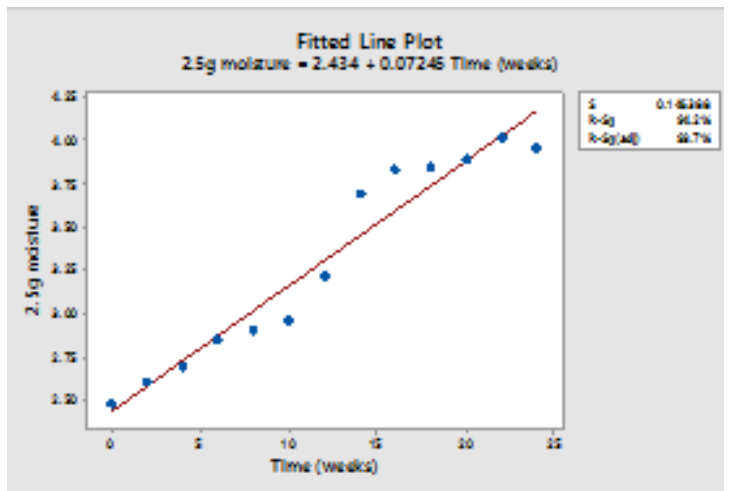

Figure 4: Fitted line plot for the rice crackers packed with

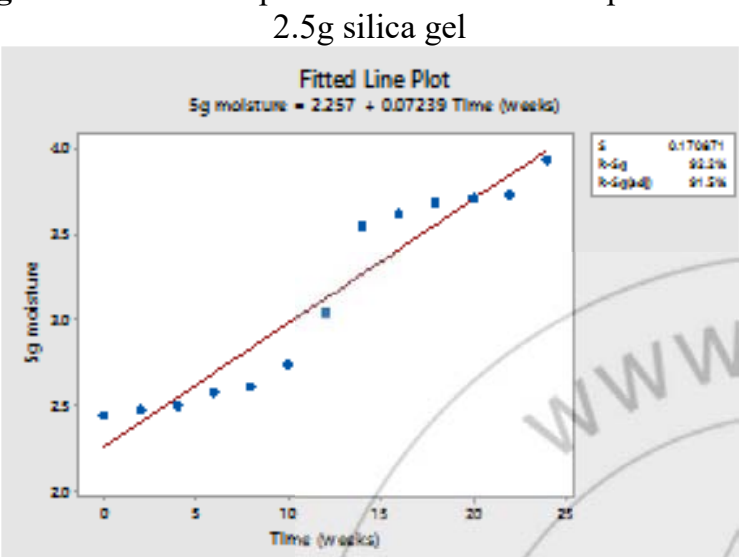

Figure 5: Fitted line plot for the rice crackers packed with $5 \mathrm{~g}$ silica gel

According to figure 2,3,4 and 5, $B$ values have decreased with the increasing amount of silica gel. The $\beta$ values for moisture content against time for the control, $1 \mathrm{~g}, 2.5 \mathrm{~g}$ and $5 \mathrm{~g}$ were $0.07643,0.07497,0.07245$ and 0.07239 . B value predicts how much the dependent variable increases with a unit increase in independent variable. In this case, lower $\beta$ value is good because it shows the effectiveness of the desiccation property of silica gel. Therefore, the sample with lower $\beta$ value is effective in providing a lower moisture content with the time. Thus, $5 \mathrm{~g}$ silica gel with a lower $\beta$ value of 0.07239 was considered to have an effective desiccation property than the other three samples.

\section{$4.5 \mathrm{pH}$ value}

Changes in the $\mathrm{pH}$ values of rice crackers packed with different amount of silica gel are shown in table 3 .

Table 3: $\mathrm{pH}$ values of rice cracker samples with time

\begin{tabular}{|c|c|c|c|c|}
\hline \multicolumn{5}{|c|}{ Rice cracker 100g packed with silica gel } \\
\hline Time (weeks) & $0 \mathrm{~g}$ & $1 \mathrm{~g}$ & $2.5 \mathrm{~g}$ & $5 \mathrm{~g}$ \\
\hline $\mathbf{0}^{\text {th }}$ & 6.14 & 6.18 & 6.15 & 6.17 \\
\hline $\mathbf{2}^{\text {nd }}$ & 6.08 & 6.16 & 6.09 & 6.15 \\
\hline $\mathbf{4}^{\text {th }}$ & 6.18 & 6.20 & 6.21 & 6.28 \\
\hline $\mathbf{6}^{\text {th }}$ & 6.24 & 6.24 & 6.24 & 6.23 \\
\hline $\mathbf{8}^{\text {th }}$ & 6.22 & 6.47 & 6.14 & 6.23 \\
\hline $\mathbf{1 0}^{\text {th }}$ & 6.33 & 6.26 & 6.42 & 6.31 \\
\hline $\mathbf{1 2}^{\text {th }}$ & 6.19 & 6.22 & 6.07 & 6.20 \\
\hline $\mathbf{1 4}^{\text {th }}$ & 6.26 & 6.33 & 6.41 & 6.42 \\
\hline $\mathbf{1 6}^{\text {th }}$ & 6.19 & 6.26 & 6.26 & 6.29 \\
\hline $\mathbf{1 8}^{\text {th }}$ & 6.14 & 6.12 & 6.17 & 6.19 \\
\hline $\mathbf{2 0}^{\text {th }}$ & 6.08 & 6.10 & 6.14 & 6.17 \\
\hline $\mathbf{2 2}^{\text {nd }}$ & 6.04 & 6.02 & 5.99 & 6.07 \\
\hline $\mathbf{2 4}^{\text {th }}$ & 5.71 & 5.72 & 5.74 & 5.80 \\
\hline
\end{tabular}

The data in the table 3 clearly indicate that there is no relationship between the amount of silica gel used and $\mathrm{pH}$ value of the rice cracker samples. However, up to $14^{\text {th }}$ week of storage, $\mathrm{pH}$ value was gradually increased with a slight variation and thereafter it was declined with time.

Decrement of $\mathrm{pH}$ value is mainly due to the development of free fatty acids and as a result of that the acidity has been increased.

According to the table 2, the highest rate of moisture gain in rice crackers was recorded from $10^{\text {th }}-14^{\text {th }}$ week. This can be attributed to the $\mathrm{pH}$ value decrement of rice crackers after $14^{\text {th }}$ weeks of storage (table 3 ). The reason for this consequence may be the hydrolytic rancidity of palm oil in the crackers which happens after an increased level of moisture absorption. Hydrolytic rancidity has resulted free fatty acids which makes the sample acidic.

\subsection{FFA value}

FFA value (oleic acid \%) variation in the rice crackers packed with different amount of silica gel with the time is shown in table 4.

Table 4: FFA content of rice cracker samples with time

\begin{tabular}{|c|c|c|c|c|}
\hline \multicolumn{5}{|c|}{ Rice cracker 100g packed with silica gel } \\
\hline Time (month) & $0 g$ & $1 g$ & $2.5 g$ & $5 g$ \\
\hline $\mathbf{2}^{\text {nd }}$ & $0.08 \%$ & $0.03 \%$ & $0.03 \%$ & $0.03 \%$ \\
\hline $4^{\text {th }}$ & $0.14 \%$ & $0.13 \%$ & $0.09 \%$ & $0.05 \%$ \\
\hline $\mathbf{6}^{\text {th }}$ & $0.21 \%$ & $0.16 \%$ & $0.13 \%$ & $0.11 \%$ \\
\hline
\end{tabular}

Table 4 indicates that the FFA value was increased in all samples with the time. The control sample recorded the highest FFA value whilst the rice crackers packed with $5 \mathrm{~g}$ silica gel recorded the lowest FFA value. FFA is formed as a result of hydrolytic rancidity which occurs by the absorption of moisture by rice crackers. Therefore, $5 \mathrm{~g}$ silica gel in the sachet was the effective treatment in lowering the development of FFA in rice crackers by retarding hydrolytic rancidity.

\subsection{Total plate count}

TPC of rice crackers packed with different amount of silica gel is shown in in table 5 .

Table 5: TPC of rice cracker samples with the time

\begin{tabular}{|c|c|c|c|c|}
\hline \multicolumn{5}{|c|}{ Rice cracker 100g packed with silica gel } \\
\hline Time (weeks) & $0 g$ & $1 g$ & $2.5 g$ & $5 g$ \\
\hline $\mathbf{0}^{\text {th }}$ & 430 & 350 & 390 & 385 \\
\hline $\mathbf{2}^{\text {nd }}$ & 520 & 407 & 317 & 444 \\
\hline $\mathbf{4}^{\text {th }}$ & 503 & 443 & 430 & 433 \\
\hline $\mathbf{6}^{\text {th }}$ & 540 & 504 & 460 & 521 \\
\hline $\mathbf{8}^{\text {th }}$ & 560 & 510 & 473 & 580 \\
\hline $\mathbf{1 0}^{\text {th }}$ & 660 & 677 & 694 & 677 \\
\hline $\mathbf{1 2}^{\text {th }}$ & 687 & 698 & 707 & 743 \\
\hline $\mathbf{1 4}^{\text {th }}$ & 767 & 800 & 733 & 767 \\
\hline $\mathbf{1 6}^{\text {th }}$ & 800 & 783 & 783 & 780 \\
\hline $\mathbf{1 8}^{\text {th }}$ & 803 & 877 & 797 & 840 \\
\hline $\mathbf{2 0}^{\text {th }}$ & 870 & 937 & 827 & 907 \\
\hline $\mathbf{2 2}^{\text {nd }}$ & 807 & 850 & 877 & 817 \\
\hline $\mathbf{2 4}^{\text {th }}$ & 860 & 820 & 803 & 770 \\
\hline
\end{tabular}




\section{International Journal of Science and Research (IJSR) \\ ISSN (Online): 2319-7064 \\ Index Copernicus Value (2015): 78.96 | Impact Factor (2015): 6.391}

According to the table 5, TPC (CFU/g) is generally increased in all the samples with time. But, there was no relationship between the total plate counts and the amount of silica gel used. Since, TPC is a measurement of all the heterotrophic and mesophilic colony counts of microorganisms, the assumption can be made as TPC is accelerated not only by moisture but by oxygen, $\mathrm{pH}$ and contaminations at the initial stage of production. Therefore, a good correlation cannot be seen between the silica gel amount and TPC.

\section{Conclusion}

The $5 \mathrm{~g}$ silica gel in sachet was the best amount to control moisture ingress into $100 \mathrm{~g}$ rice cracker packet. Variation of $\mathrm{pH}$ values and total plate counts of rice crackers did not show any relationship with the silica gel amount used. The $5 \mathrm{~g}$ silica gel in sachet was able to control the development of FFA in the rice crackers by retarding the hydrolytic rancidity. Based on the texture profile analysis, $5 \mathrm{~g}$ silica gel was able to impart lower hardness in crackers which implies a good crispiness. Therefore, $5 \mathrm{~g}$ silica gel should be used in the $100 \mathrm{~g}$ rice cracker packets as the desiccant because it was capable to impart favorable properties on the physical and chemical properties of the product throughout its shelf life.

\section{Acknowledgment}

Author would like to thank the academic and non-academic staff of University of Sri Jayewardenepura.

\section{References}

[1] Al-Shawabkeh, A.F. and Mazahreh, A.S., 2009. Evaluation of Fat and Vitamin E in Some Cookies Diet. Pakistan Journal of Nutrition, 8(3), pp.214-217.

[2] Brody, A.L., Strupinsky, E.P. and Kline, L.R., 2001. Active packaging for food applications. CRC press.

[3] Chui, M.Y., 2002. Functional qualities of rice for high temperature food processing. 香港大學學位論文, pp. 1-0.

[4] Joshi, N.D., Mohapatra, D. and Joshi, D.C., 2014. Varietal selection of some indica rice for production of puffed rice. Food and Bioprocess Technology, 7(1), pp.299-305

[5] Lawless, H.T. and Heymann, H., 2010. Sensory evaluation of food: principles and practices. Springer Science \& Business Media.

[6] Maneerote, J., Noomhorm, A. and Takhar, P.S., 2009. Optimization of processing conditions to reduce oil uptake and enhance physico-chemical properties of deep fried rice crackers. LWT-Food Science and Technology, 42(4), pp.805-812.

[7] Marsh, K.S., 1997. Wiley encyclopedia of packaging technology. Wiley.

[8] Meiselman, H.L., 1996. The contextual basis for food acceptance, food choice and food intake: the food, the situation and the individual. In Food choice, acceptance and consumption (pp. 239-263). Springer US.
[9] Orthoefer, F.T., 2005. Rice bran oil. Bailey's industrial oil and fat products.

[10]Poku, K., 2002. Small-scale palm oil processing in Africa (Vol. 148). Food \& Agriculture Org..

[11] Rajkumar, V., Moreira, R. and Barrufet, M., 2003. Modeling the structural changes of tortilla chips during frying. Journal of Food Engineering, 60(2), pp.167-175.

[12] Robertson, G.L., 2006. Food Packaging Principles and Practice. Boca Raton, Florida: CRC Press, pp. 61, 417446.

[13] Sedej, I., Sakač, M., Mandić, A., Mišan, A., Pestorić, M., Šimurina, O. and Čanadanović-Brunet, J., 2011. Quality assessment of gluten-free crackers based on buckwheat flour. LWT-Food Science and Technology, 44(3), pp.694-699.

[14] Singh, R., Singh, G. and Chauhan, G.S., 2000. Nutritional evaluation of soy fortified biscuits. Journal of food science and technology, 37(2), pp.162-164.

\section{Author Profile}

A. M. Suweesha H. Amarakoon is a final year (2016) student in Department of Food Science and Technology at University of Sri Jayewardenepura. She is eligible for B.Sc (Special) degree in Food Science and Technology. She has completed this research project successfully under the expert guidance of Senevirathne Navaratne, Professor in Food Science and Technology who holds a B.Sc in Agriculture Engineering, M.Phil in Food Science and Technology and $\mathrm{PhD}$ in Food Processing Engineering. 